\title{
Relações entre a natureza e a literatura no pensamento de Italo Calvino.
}

\section{Bruna Fontes Ferraz, UFMG}

Resumo: Neste trabalho, pretendemos evidenciar uma relação de equivalência entre natureza e literatura no pensamento do escritor italiano Italo Calvino. Considerando a capacidade produtora da literatura, que cria mundos possíveis, percorreremos o conceito de uma literatura como antiphysis que, através do jogo, da técnica e do artifício, tem a palavra como a própria natureza e não mais como um eco ou uma imitação de uma natureza perdida.

Palavras-chave: Relação entre natureza e literatura; Antiphysis; Italo Calvino.

O que era a natureza? Ervas, plantas, lugares verdes, animais. Eu vivia no meio daquilo e queria estar em outro lugar. Diante da natureza permanecia indiferente, reservado, por vezes hostil. E não sabia que eu também estava buscando uma relação, talvez mais afortunada que a de meu pai, uma relação que a literatura acabaria me dando, devolvendo significado a tudo, e, de repente, cada coisa se tornaria verdadeira e tangível e possuível e perfeita, cada coisa daquele mundo já perdido.

Italo Calvino

Nesta citação - retirada do ensaio "O caminho de San Giovanni", incluído em livro homônimo -, Italo Calvino, ao declarar como sua relação com a natureza evoluiu de hostil a uma relação mediada pela literatura, parece levantar um questionamento já muito presente e muito discutido nos estudos sobre a teoria da literatura: se esta imitaria a natureza. Podemos considerar, nesse sentido, que a presença da natureza seria determinante para a formação intelectual de Calvino, ou por negá-la, revelando estar mais interessado por aquilo que lhe pareceria contrário ao natural, ou seja, a cidade, o cinema, a literatura, ou por retomá-la, ao acreditar que a literatura, tal qual a natureza, devolveria significado a tudo.

Assim, nesse ensaio, o escritor italiano faz um exercício de rememoração dos anos de sua infância e adolescência, nos quais o seu mundo era dividido em dois continentes, sendo sua casa a fronteira entre eles: para baixo em direção à cidade e para cima rumo ao campo. Enquanto o pai de Calvino só se interessava pelo caminho que ia de sua casa para cima, procurando pelos mistérios da natureza, o olhar do jovem Calvino estava ávido pelas luzes, sons e agitação da cidade. Nesse sentido, refletindo sobre sua relação com a natureza - relação esta motivada pelo interesse dos pais (seu pai era agrônomo, sua mãe botânica) ${ }^{1}$ - Calvino se conscientiza, como vimos na citação acima, de sua atitude indiferente e hostil frente aos animais e às plantas, pois acreditava que ele e seu pai seguiam caminhos díspares, o pai interessado pelo reino vegetal, o filho atraído "por outra vegetação, a das frases escritas". ${ }^{2}$

No entanto, se durante a sua infância, o jovem Calvino não percebia que ele também estava buscando, tal como seu pai, uma relação com a natureza, quando já um escritor consolidado percebe que a literatura viabilizaria essa relação, por serem ambas geradoras de vida, de significados. Assim, o escritor italiano traça não só a relação entre literatura e natureza, como também as afinidades entre o seu caminho e o de seu pai, pois que suas escolhas não os levavam mais a caminhos diferentes: 
Afinal, que caminho eu buscava senão o mesmo de meu pai, cavado na densidão de outra estranheza, no supramundo (ou inferno) humano? O que buscava com o olhar pelos átrios mal iluminados da noite (a sombra de uma mulher, às vezes, desaparecia ali) senão a porta entreaberta, a tela do cinema a ser atravessada, a página a ser virada que introduz num mundo em que todas as palavras e figuras pudessem se tornar reais, presentes, experiência minha, não mais o eco de um eco de um eco? ${ }^{3}$

Tal como seu pai, Calvino também buscava, muitas vezes, entender a natureza, mas a natureza humana, imerso que estava nesse "supramundo humano", almejando que cada virada de página pudesse introduzir um novo mundo e não simplesmente imitá-lo ou representá-lo. O escritor italiano queria, assim, tornar as palavras reais e presentes, não mais o eco que evoca a coisa propriamente dita. Entretanto, ao afirmar que a literatura mediaria sua relação com a natureza, podemos nos questionar se Calvino não estaria sendo incoerente, visto que tanto a literatura moderna, quanto a própria literatura calviniana procurariam romper, justamente, com qualquer contato imitativo que pudesse existir entre a arte e a natureza.

A relação entre a literatura e a natureza, desde a Poética, de Aristóteles, é o caminho mais corrente para se refletir sobre a própria definição da literatura, a qual era comumente entendida como mímesis. Para Aristóteles, a epopeia, a tragédia e a comédia se enquadravam nas artes de imitação, sendo que esta capacidade imitativa seria intrínseca ao homem. Entretanto, o filósofo grego já ressaltava que a imitação seria produzida por meio "do ritmo, da linguagem e da harmonia", ${ }_{4}$ ou seja, a mímesis seria mediada pela linguagem, o ritmo e a harmonia para promover seu contato com a natureza; não havendo assim uma relação tão imediata, como poderíamos pensar num primeiro momento, entre a literatura e a natureza.

Segundo Hans Blumenberg (2010), Aristóteles, ao apresentar a formulação de que a "arte é imitação da natureza", definia o conceito de tékhne, que para os gregos resultava no poder de atuação dos homens no real, o qual era entendido não só como "técnica", mas como "todas as habilidades humanas de operar e configurar, que abrange o que hoje tão fortemente distinguimos: tanto o 'artificial' como o 'artístico"". ${ }^{5}$ Diante dessas considerações, podemos evidenciar como o legado aristotélico tem sido subvertido ao longo de todos esses anos, já que o próprio filósofo grego não desconsiderava a técnica, o fazer artístico como uma produção artificial, de modo que os artistas não imitariam o que a natureza teria de essencial e perfeito, como consideraram os renascentistas em sua releitura de Aristóteles, pois "não é ofício de poeta narrar o que aconteceu; é, sim, o de representar o que poderia acontecer, quer dizer: o que é possível segundo a verossimilhança e a necessidade". ${ }^{6}$

Embora Aristóteles relacionasse a mímesis ao sentido natural, ele invocava a produção de uma ficção verossímil, que estaria no âmbito das possibilidades, de como as coisas poderiam ter acontecido. Diante disso, o filósofo ressaltava a importância da persuasão nas artes imitativas, pois de nada adiantaria ser a arte imitadora da natureza, caso não fosse também persuasiva: "é preciso preferir o que é impossível mas verossímil ao que é possível mas não persuasivo", pois "um impossível persuasivo é preferível ao nãopersuasivo, ainda que possível". ${ }^{7}$ Aristóteles, assim, evidenciava o caráter ficcional da arte poética.

Se a mímesis era entendida, para Aristóteles, em sua relação com a natureza, para a modernidade, ela se torna "a verossimilhança em relação ao sentido cultural". ${ }^{8} \mathrm{O}$ princípio de referencialidade externa foi, portanto, questionado pela literatura moderna que "insistiu na autonomia da literatura em relação à realidade, ao referente, ao mundo, e defendeu a tese do primado da forma sobre o fundo, da expressão sobre o conteúdo, do significante sobre o significado, da significação sobre a representação". ${ }^{9}$ Ao perpetuar uma incessante ruptura com a tradição, buscando sempre "criar o novo", tal como 
denuncia Antoine Compagnon em Os cinco paradoxos da modernidade, a arte contemporânea passa a ser concebida como um jogo autônomo de palavras, no qual há a perda da função representativa e referencial em função de sua auto-referencialidade: "O modernismo, então, se torna a procura de uma arte-objeto pura, auto-referida". ${ }^{10}$

Calvino, por sua vez, não rompe totalmente com a natureza, como vimos em seu ensaio "O caminho de San Giovanni", pois, a seu ver, a literatura moderna procuraria uma relação inovadora com a natureza, no sentido de serem estruturalmente equivalentes. Ao trazer à superfície da memória lembranças de seu pai, Calvino percebe que eles buscavam adentrar em outros mundos, em mundos que acabariam se assemelhando pela necessidade de confrontar o "que resta fora": o pai com o intuito de resgatar cada coisa daquele mundo já perdido, o mundo natural, enquanto o filho, pela entrada no mundo da literatura, percebia que as palavras se tornavam reais, ou seja, pela própria capacidade produtora da literatura, de criar outras realidades, a palavra se tornaria a própria natureza e não mais um eco ou uma imitação de uma natureza perdida:

Mas o que movia meu pai a cada manhã pelo caminho de San Giovanni acima - e a mim abaixo, pelo meu caminho -, mais que o dever de proprietário laborioso, ou o desprendimento de inovador de métodos agrícolas - e o que movia a mim, mais que as definições daqueles deveres que aos poucos iria me impor -, era a paixão feroz, dor de existir - o que mais podia nos impelir, ele a subir pragais e bosques, eu a me entranhar num labirinto de muros e papéis escritos? -, confronto desesperado com o que resta fora de nós, desperdício de si em oposição ao desperdício geral do mundo. ${ }^{11}$

Esse confronto desesperado com o que resta fora impelia pai e filho pela paixão com a qual executavam seus respectivos trabalhos - o pai se entranhando em bosques e o filho nos labirintos da escrita - para que pudessem desvendar os mistérios da natureza, no caso do primeiro $_{2}$ e traçar sua relação enquanto modelo para a arte, como pretendia o filho. Calvino, então, reconhece haver certa relação entre a literatura e a natureza, mas não uma relação mediada pelo princípio da imitação - entendimento que se inicia com Aristóteles e que se dissemina até o século XVIII ao tentar explicar o processo de criação artística como imitação da natureza -, e sim proporcionada pela capacidade de produção e criação conferida tanto à natureza quanto à literatura. Rompendo com o princípio representativo da arte enquanto imitação da natureza, a poética da modernidade, ao enfatizar suas próprias diferenças, não pretende mais estender seu domínio ao âmbito do real, para abarcar também temas insólitos, buscando criar formas, imagens e realidades próprias.

Diante dessa perspectiva, pretendemos identificar como a natureza é tratada na literatura calviniana enquanto simulação, jogo de ilusões, técnica e artifício, já que a arte "significa um produzir que dá forma, um fabricar que engendra, uma criação que organiza, ordena e instaura uma realidade nova"; ${ }^{12}$ ou seja, uma literatura concebida como antiphysis, segundo considera Luiz Costa Lima em seu texto "A antiphysis em Jorge Luis Borges".

Pensar na natureza do fazer artístico implicitamente realça o papel da mímesis. Assim, se a literatura enquanto physis tinha por alvo de representar a natureza, estabelecendo um relacionamento de semelhança com esta; a literatura como antiphysis, por sua vez, enfatiza a palavra, a linguagem, supondo que a mímesis se realiza na superfície de sua escritura. Por isso, refletiremos tanto sobre a própria natureza da experiência ficcional calviniana, a partir do conto "Um sinal no espaço", quanto sobre a possibilidade de uma literatura enquanto jogo, produção cultural, que incita, muitas vezes, uma suspensão da realidade.

Desse conto, vale ressaltar, primeiramente, que ele faz parte de uma lógica maior de produção literária, pois se inclui no projeto "cosmicômico" de Calvino, que alia teorias científicas à literatura. "Um sinal no espaço", encontrado na obra As cosmicômicas (1965) - ou seja, obra definida sob a lógica do jogo, espaço de disputa entre liberdade e 
restrição -, é narrado pelo protagonista de nome impronunciável, Qfwfq, e procura retratar um mundo ainda em formação, uma natureza em devir, no qual a própria palavra vem antes de tudo.

Em "Um sinal no espaço", ao narrar sobre a criação do nosso universo, o protagonista das histórias cosmicômicas, Qfwfq, revela-nos a presença de uma natureza que vai se constituindo com signos e sinais, tal como uma página em branco. Objetivando mensurar o tempo que o sol leva "para realizar uma revolução completa da Galáxia", ${ }^{13}$ o protagonista de nome impronunciável faz um sinal no espaço, mas como ainda "não havia nada que pudesse distinguir-se de nada", ${ }^{14}$ o seu sinal acaba se tornando uma representação originária, produzido pela imaginação e vontade de Qfwfq em se expressar:

[...] naquela época não havia exemplos aos quais referir-me para saber se o fazia igual ou diverso de outro, não havia coisas que se pudessem copiar, nem mesmo uma linha reta ou curva que fosse, não se sabia o que era, nem um ponto, uma saliência ou reentrância. Tinha a intenção de fazer um sinal, isto sim, ou seja, tinha a intenção de considerar sinal uma coisa qualquer que me ocorresse fazer, donde tendo eu, naquele ponto do espaço e não em outro, feito algo com a intenção de fazer um sinal, resultou em verdade que acabei fazendo um sinal. ${ }^{15}$

A inexistência de algo que se pudesse copiar faz do sinal de Qfwfq único, constituindo-o como o termo de comparação para todos os futuros sinais, os quais deveriam imitar o primeiro. A possibilidade de criação do sinal admitiu, portanto, o surgimento de todas as outras coisas a se formar no universo, ou seja, a presença do sinal permitiu que "o sentido da visão [começasse] em nosso mundo, e consequentemente também a vida", ${ }^{16}$ tornando-se referência e modelo para todas as outras criações. O protagonista das cosmicômicas é, nesse sentido, como um deus, capaz de produzir e criar seus próprios sinais sem, contudo, imitar um outro preexistente.

Assim, ansioso por reencontrar a sua criação, a sua obra, Qfwfq, que "na garupa da Galáxia percorria os anos-luz corcoveando sobre órbitas planetárias e estelares como na sela de um cavalo" ${ }^{17}$ teve o desgosto de encontrar, no lugar do seu sinal, "um esfregaço informe, uma abrasão do espaço, deteriorada e carcomida". ${ }^{18}$ Além de ter o seu sinal destruído, Qfwfq percebe também que outros sinais foram feitos por um certo Sr. Kgwgk, "tipo despeitado e roído pela inveja, que num impulso vandálico havia apagado [o] sinal e depois tentara com grosseiro artifício fazer um outro em seu lugar". ${ }^{19} \mathrm{O}$ primeiro sinal criado, aquele que "havia nascido antes do início de todas as formas", ${ }^{20}$ foi copiado, imitado por outros seres, mas para o herói calviniano qualquer sinal semelhante, copiado do seu seria tosco, "impreciso e absurdamente pretensioso". ${ }^{21}$

O sinal de Kgwgk, por ser meramente imitativo, é só uma cópia imprecisa, diferentemente das outras formas do mundo que surgiram após o sinal de Qfwfq, pois, embora pudessem partir da marca do protagonista como ponto de referência, conseguiram, por sua vez, questioná-la, ressaltando assim seu próprio aspecto de originalidade. Essa relação estabelecida pelos sinais no conto de Calvino nos faz refletir sobre a própria relação da arte com a natureza, pois se a arte clássica esteve, durante muito tempo, marcada pelo axioma de representar e imitar as coisas naturais e reais, a arte moderna questionaria a confiança na physis e se basearia na própria linguagem (como nos parece corroborar o conto "Um sinal no espaço", já que o sinal de Qfwfq surgiu antes da natureza, logo, tal como o Sr. Kgwgk, deve-se imitar o sinal, o signo, a palavra e não a natureza).

Nesse sentido, a literatura moderna dissolve o real tomando-o como limite entre o possível e o impossível e rompendo com qualquer correspondência que poderia se estabelecer com a physis, pois a literatura enquanto antiphysis desagrega referências e 
identificações e "passa a significar multiplicação de falsas correspondências". ${ }^{22}$ Assim, para Luiz Costa Lima:

A ficção tramada neste contexto [...] faz-se vida simulada, invenção da vida impossível e não da que poderia ter sido. Esta ficção não remete, sequer como instância mediatizada, a formas de existência, mas sim a um encaixe de ficções, livros dentro de livros, comentários ficcionais a textos também ficcionais, onde figuras muitas vezes reais, [...], remetem a diálogos ficcionais e relatos ficcionais fingem-se relatos do real. ${ }^{23}$

Temos, então, que a literatura produz simulacros, os quais, por gerar dissimilitude, perversão e desvio, potencializam o falso a fim de produzir um efeito; diferentemente do que pretendia Platão ao considerá-los cópias de terceiro grau por não buscarem semelhança com a Ideia, mas com a primeira cópia desta Ideia. Essa revalorização dos simulacros - os quais definem o próprio caráter ficcional ao permitir a criação de mundos possíveis pelos jogos de linguagem -, foi apresentada por Gilles Deleuze (2007) em seu texto "Platão e o simulacro" ao propor reverter o platonismo e afirmar os direitos dos simulacros entre os ícones ou as cópias. Deleuze define a modernidade, assim, pela potência do simulacro, já que "o simulacro não é uma cópia degradada, ele encerra uma potência positiva que nega tanto o original como a cópia, tanto o modelo como a reprodução". ${ }^{24}$ Ao simulacro cabe, portanto, a força produtiva e geradora das artes que têm o "falso como potência", ${ }^{25}$ ou seja, a partir da ficção, criam-se vidas e mundos simulados e, por mais que estes pareçam semelhantes aos reais, "o Mesmo e o Semelhante tornam-se simples ilusões, precisamente a partir do momento em que deixam de ser simulados". ${ }^{26}$

O fazer artístico, pois, se define como potência do falso, como puro artifício, cuja relação deixa de ser mediada pelo natural, e passa a ser estabelecida pela técnica empregada em sua produção, pela potência da ficção. Diante disso, podemos concluir com Blumenberg que "entre a natureza e a técnica, não há mais uma fronteira definida, (...): a 'arte' é a natureza por outros meios". ${ }^{27}$ A literatura seria, assim, estruturalmente equivalente à natureza, por sua capacidade de criar outros mundos, pois "a poesia não é apenas uma imitação da criação e da natureza do real senão que também do possível". ${ }^{28}$ Tal foi a estratégia utilizada por Calvino em sua obra As cosmicômicas, tomando como matéria de sua criação, a imaginação. Diante disso, por mais que o escritor italiano recorra a dados do real e da ciência para escrever seus contos, ele desvia e deturpa tais lógicas buscando produzir "coisas que não são", simulando "fatos que não aconteceram" e perpetuando um diálogo constante com a própria literatura.

A literatura calviniana supera, pois, o tradicional axioma de que a arte é imitação da natureza, ao buscar a sua simulação. Dessa forma, o escritor italiano parece alcançar uma relação muito mais afortunada com a natureza, pois através da literatura, ele se coloca como um "alter deus" que pode fundar uma "natura altera" ${ }^{29}$ para usarmos os termos mencionados por Blumenberg em seu texto "'Imitação da natureza': contribuição à préhistória da ideia do homem criador", tornando, pela linguagem, tudo mais verdadeiro, possuível e perfeito, como considerou Calvino em seu texto "O caminho de San Giovanni", pois "a obra de arte não mais quer significar algo; ela quer ser algo". ${ }^{30}$

A arte e, consequentemente, a literatura, enquanto antiphysis, ao superar a representação imediata do real, busca, por meio do jogo, criar um universo próprio, uma outra realidade, distanciando-se do postulado da imitação da natureza, pois o jogo cria um sistema próprio de regras combinando em si as ideias de limite, liberdade e invenção. Assim, pelo viés do jogo, o texto pode criar um mundo próprio que em muitos aspectos divergiria da vida real, ao propor uma "suspensão sobre a realidade", conforme considera Roger Caillois em seu livro Los juegos y los hombres.

Nesse sentido, ao suspender qualquer referência ao mundo externo e real, o jogo cria um universo fechado centrando-se, muitas vezes, em si mesmo. O jogo, então, se 
definiria para Hans-Georg Gadamer (1998) como "o próprio modo de ser da obra de arte", ${ }^{31}$ já que ele tem uma natureza própria, funda sua própria natureza a partir das regras e restrições impostas. Diante disso, poderíamos pensar na própria literatura de Calvino, em sua obra As cosmicômicas, como jogo ${ }^{32}$, pois ao se valer de regras - como o próprio postulado científico no qual se baseia para continuar criando e escrevendo seus contos - trata a literatura enquanto um universo fechado em si mesmo, fechado na própria linguagem, buscando uma maior proximidade com o caráter experimental da arte e da ciência, ao partir de uma para criar a outra e vice-versa.

Nessa lógica, há sempre a imprevisibilidade e o elemento de surpresa marcando o jogo e, consequentemente, a literatura que se vale da ordem do jogo, já que este vive de suas potencialidades, criando um universo onde tudo pode acontecer. Ao jogar, o jogador deve aceitar as regras do jogo, adentrando, muitas vezes, num outro princípio e ordenamento das regras, pois assume o comportamento de aceitar o jogo como um outro mundo e não mais como um simples objeto: "O modo de ser do jogo não permite que quem joga se comporte em relação ao jogo como em relação a um objeto. Aquele que joga sabe muito bem o que é o jogo e que o que está fazendo é 'apenas um jogo', mas não sabe o que ele 'sabe' nisso". ${ }^{33}$

A mesma postura assumida pelo jogador, também é assumida por um leitor de uma obra ficcional, o qual deve aceitar deliberadamente as regras da obra, por mais que a reconheça enquanto um texto literário. No caso d'As cosmicômicas - que ao tratar de uma temática puramente ficcional e que não se inclui na lógica do que poderia ter acontecido na vida real, tal como considerava Aristóteles - pode parecer difícil que o leitor assuma o pacto de leitura exigido. No entanto, os contos cosmicômicos apresentam uma regra interna tão rigorosa (característica do jogo) que levam o leitor a adentrar nesse outro mundo criado por Calvino e seu protagonista que viaja no tempo e, ao experimentar esse jogo, acaba sendo arrebatado. Por mais que a temática retratada n'As cosmicômicas baseie-se no impossível ${ }_{2}$ assumindo, em muitos aspectos, características em comum com a literatura fantástica, a obra, enquanto persuasiva, é preferível àquela não persuasiva, mas possível segundo as regras da realidade, como muito bem observou Aristóteles em sua Poética.

É, sobretudo, a obra literária que explora fatos impossíveis, fantásticos e autorreferenciais que mais resulta na característica produtiva da literatura a qual equivale à natureza. Produzir a literatura, tal como um jogo, irá permitir a criação de outros universos, já que "também o seu jogar é um acontecimento da natureza. Também o sentido de seu jogar, justamente por ele ser, e na medida em que é natureza, é um puro representar-se a si mesmo". ${ }^{34}$ A literatura enquanto produtora de simulacros, de ficção centra-se na própria linguagem e na própria literariedade, desvendando um mundo interno, autorreferencial que, por vezes, é muito mais reflexivo do que aquele no qual vivemos.

Assim, a literatura extrapola uma imitação escravizada da natureza, se tornando equivalente a esta: "A natureza, na medida em que existe sem finalidade e intenção, inclusive sem esforço, e enquanto é um jogo que sempre se renova, pode, por isso mesmo, surgir como um modelo da arte". ${ }^{35}$ Calvino, nesse sentido, ao escrever, joga com possibilidades, num jogo que se baseia em liberdade e restrição, mas ao criar o seu próprio mundo ficcional, o qual, por vezes, é metarreferencial, busca uma iluminação ao mundo não escrito, ao mundo real, pois, embora seja o jogo instaurador de um mundo fechado, o próprio Gadamer já aludia à queda de uma parede que permitiria ao espetáculo relacionar-se com seus espectadores. A obra calviniana, por mais fantástica que seja, como As cosmicômicas, permite uma relação de analogias, de iluminação entre um universo e outro, entre o mundo escrito e o mundo não escrito.

Numa literatura enquanto antiphysis, pautada no jogo, o que se tece em relação ao mundo não pode ser pensado numa perspectiva de imitação, mas na de analogias decorrentes de sua capacidade de simbolização. A literatura calviniana, portanto, passa a aludir a ela mesma, embora possa também aludir a referenciais externos, já que tanto a 
literatura quanto o mundo cosmicômico parecem "ser o espelho um do outro, um e outro minuciosamente historiados de hieróglifos e ideogramas, cada qual podendo ser um sinal ou não ser". 36

\begin{abstract}
This paper aims to discuss the equivalence relation between nature and literature according to the Italian writer Italo Calvino. Taking into account literature's productive capacity, which can create possible worlds, we discuss the concept of literature as antiphysis which, through the game, the art and the artifice, considers the word as nature itself, not as an echo or an imitation of a lost nature.
\end{abstract}

Keywords: Relation between nature and literature; Antiphysis; Italo Calvino.

\title{
Referências Bibliográficas
}

ARISTÓTELES. Poética. Tradução de Eudoro de Souza. São Paulo: Abril, 1973.

BERMAN, Marshall. Introdução: Modernidade - Ontem, Hoje e Amanhã. BERMAN, Marshall. Tudo que é sólido desmancha no ar: a aventura da modernidade. Tradução de Carlos Felipe Moisés e Ana Maria L. Ioriatti. São Paulo: Companhia das Letras, 1986. p. $15-35$.

BLUMENBERG, Hans. "Imitação da natureza": contribuição à pré-história da ideia do homem criador. In: LIMA, Luiz Costa (org.). Mímesis e a reflexão contemporânea. Rio de Janeiro: EdUERJ, 2010. p. 87-135.

CAILLOIS, Roger. Los juegos y los hombres: la máscara y el vértigo. Traducción de Jorge Ferreiro. México D. F.: Fondo de Cultura Económica, 1984.

CALVINO, Italo. Um sinal no espaço. In: CALVINO, Italo. As cosmicômicas. Tradução de Ivo Barroso. São Paulo: Companhia das Letras, 1992. p. 35-44.

CALVINO, Italo. O caminho de San Giovanni. In: CALVINO, Italo. O caminho de San Giovanni. Tradução de Roberta Barni. São Paulo: Companhia das Letras, 2000. p. 15-38.

CALVINO, Italo. Nota à edição italiana de 1996. In: CALVINO, Italo. Eremita em Paris: páginas autobiográficas. Tradução de Roberta Barni. São Paulo: Companhia das Letras, 2006. p. 9-11.

COMPAGNON, Antoine. Os cinco paradoxos da modernidade. Tradução de Cleonice P. Mourão, Consuelo F. Santiago e Eunice D. Galéry. Belo Horizonte: Ed. UFMG, 1996. 
COMPAGNON, Antoine. O mundo. In: COMPAGNON, Antoine. O demônio da teoria: literatura e senso comum. Tradução de Cleonice Paes Barreto Mourão e Consuelo Fortes Santiago. Belo Horizonte: Ed. UFMG, 2001. p. 97-138.

DELEUZE, Gilles. Platão e o simulacro. In: DELEUZE, Gilles. Lógica do sentido. Tradução de Luiz Roberto Salinas Fortes. São Paulo: Perspectiva, 2007. p. 259-271.

GADAMER, Hans-Georg. A ontologia da obra de arte e seu significado hermenêutico. In: GADAMER, Hans-Georg. Verdade e Método. Tradução de Flávio Paulo Meurer. Petrópolis: Vozes, 1997. p. 174-219.

LIMA, Luiz Costa. A antiphysis em Jorge Luis Borges. In: LIMA, Luiz Costa. Mímesis e modernidade: formas das sombras. Rio de Janeiro: Graal, 1980. p. 229-258.

NUNES, Benedito. Introdução à filosofia da arte. São Paulo: DESA, 1966.

\section{Notas}

${ }^{1}$ Por ser filho de cientistas numa família que só prestigiava os estudos científicos, Calvino afirma se sentir a ovelha negra da família por não ter escolhido, conforme seus pais e seu irmão, a área das ciências naturais e ter optado pela literatura.

${ }^{2}$ CALVINO. Nota à edição italiana de 1996, p. 10.

${ }^{3}$ CALVINO. O caminho de San Giovanni, p. 21.

${ }^{4}$ ARISTÓTELES. Poética, p. 443.

${ }^{5}$ BLUMENBERG. Imitação da natureza: contribuição à pré-história da ideia do homem criador, p. 87.

${ }^{6}$ ARISTÓTELES. Poética, p. 451.

${ }^{7}$ ARISTÓTELES apud COMPAGNON. O mundo, p. 105-106.

${ }^{8}$ COMPAGNON. O mundo, p. 102.

${ }^{9}$ COMPAGNON. O mundo, p. 97.

${ }^{10}$ BERMAN. Introdução: Modernidade - Ontem, Hoje e Amanhã, p. 29.

${ }^{11}$ CALVINO. O caminho de San Giovanni, p. 26.

${ }^{12}$ NUNES. Introdução à filosofia da arte, p. 32.

${ }^{13}$ CALVINO. Um sinal no espaço, p. 35.

${ }^{14}$ CALVINO. Ibidem, p. 35.

${ }^{15}$ CALVINO. Ibidem, p. 36.

${ }^{16}$ CALVINO. Ibidem, p. 40.

${ }^{17}$ CALVINO. Ibidem, p. 39.

${ }^{18}$ CALVINO. Ibidem, p. 39.

${ }^{19}$ CALVINO. Ibidem, p. 40.

${ }^{20}$ CALVINO. Ibidem, p. 42.

${ }^{21}$ CALVINO. Ibidem, p. 40.

${ }^{22}$ LIMA. A antiphysis em Jorge Luis Borges, p. 239.

${ }^{23}$ LIMA, A antiphysis em Jorge Luis Borges, p. 241.

${ }^{24}$ DELEUZE. Platão e o simulacro, p. 267. 
${ }^{25}$ DELEUZE. Ibidem, p. 268.

${ }^{26}$ DELEUZE. Ibidem, p. 270.

${ }^{27}$ BLUMENBERG. Imitação da natureza, p. 111.

${ }^{28}$ BLUMENBERG. Ibidem, p. 132.

${ }^{29}$ BLUMENBERG. Ibidem, p. 131.

${ }^{30}$ BLUMENBERG. Ibidem, p. 134.

${ }^{31}$ GADAMER. A ontologia da obra de arte e seu significado hermenêutico, 174.

${ }^{32}$ A interface entre a literatura e o jogo teve seu auge na produção calviniana durante o seu ingresso no grupo literário-matemático Oulipo (Ouvroir de Littérature Potentielle Ateliê de Literatura Potencial), o qual defende uma escrita pré-determinada que vise à aplicação meticulosa de regras para a criação de obras literárias.

${ }^{33}$ GADAMER. A ontologia da obra de arte e seu significado hermenêutico, p. 175.

${ }^{34}$ GADAMER. Ibidem, p. 179.

${ }^{35}$ GADAMER. Ibidem, p. 179.

${ }^{36}$ CALVINO. Um sinal no espaço, p. 43. 